\title{
Chronic obstructive pulmonary disease day - a traditional strategy of the Romanian Society of Pneumology
}

\section{Florin Mihălțan*, Ruxandra Ulmeanu, Roxana Nemeș, Ramona Nedelcu}

"Marius Nasta" Institute of Pneumophtysiology, Bucharest, Romania

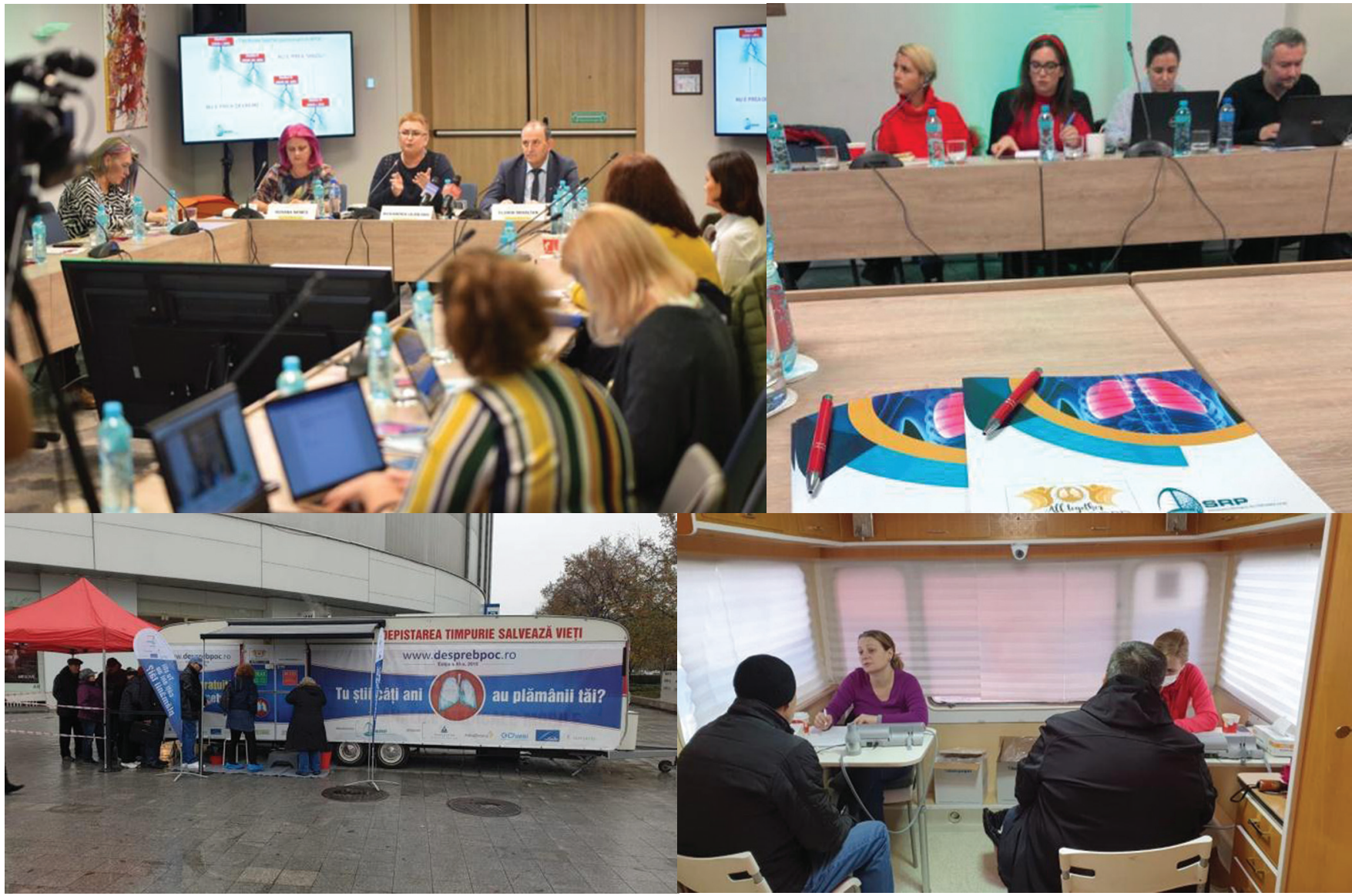

We arrived slowly this year to the XI edition of the "World COPD Day" organised and celebrated by the Romanian Society of Pneumology. Chronic obstructive pulmonary disease (COPD) is now estimated to be the fourth leading cause of death globally and is also a major cause of poor quality of life, early retirement and absenteeism, which causes distress to individuals and their families and challenge for employers. "World COPD Day" is organised every year by the "Global Initiative for Chronic Obstructive Lung Disease" (GOLD) in collaboration with healthcare professionals and COPD patient groups throughout the world. Its aim is to raise awareness about COPD and to improve COPD care throughout the world. For 2019, the message was "All together to end COPD" with a very optimistic and stimulating logo. The first "World COPD Day" was

${ }^{*}$ Corresponding author: Florin Mihălțan

"Marius Nasta" Institute of Pneumophtysiology, Sos. Viilor 90, Sector 5, Bucharest, Romania. E-mail: mihaltan@starnets.ro 
held in 2002. Each year organisers in more than 50 countries worldwide carry out activities, making the day one of the world's most important COPD awareness and education events. To the press conference the leaders of the "Romanian Society of Pneumology" Board discussed about the strategy choosed for our country to control this disease. Professor Ulmeanu Ruxandra presented the results of the second inquiry on prevalence of COPD in Romania organised in 2017-2018. With a prevalence of $8.3 \%$ in 2018 versus $8.13 \%$ in 2012 , COPD remains a challenging problem for the authorities and also for the system, connected in the same time to the multiple associated risk factors such as smoking and pollution. Professor Florin Mihăltan spoke about the last 3 years of spirometry screening organised yearly after these events with almost $27.3 \%$ of pulmonary dysfunction discovered in 2018 to the last spirometry testing in the sample of investigated populations. Finally, Associate Professor
Roxana Nemeș described for the journalists the value and the technique of spirometry. We had also a testimonial of a patient with COPD diagnosed 10 years ago who was talking about his experience and the benefits of the therapy. At the end of the week just after the press conference, as usually with support of the sponsors, it was organised in "Piața Unirii" the new screening of spirometry, announced in a media release for the inhabitants of the capital. We succeeded to screen more than 300 people in these two days. This "World COPD 2019 Day" was a good opportunity to reflect on whether people with COPD are being offered the support they need. Early diagnosis and early pharmacological intervention can improve the health status and exercise capacity of COPD patients, and reduce exacerbations, even in those with mild to moderate COPD. These are and remain the main objectives of the Romanian Society of Pneumology for fighting against the burden of this chronic obstructive disease. 